\title{
BMJ Open Do conceptualisations of health differ across social strata? A concept mapping study among lay people
}

\author{
Karien Stronks, ${ }^{1}$ Nancy Hoeymans, ${ }^{2}$ Beatrijs Haverkamp, ${ }^{3}$ Frank R J den Hertog, ${ }^{4}$ \\ Marja J H van Bon-Martens, ${ }^{5}$ Henrike Galenkamp, ${ }^{1}$ Marcel Verweij, ${ }^{3}$ \\ Hans A M van Oers ${ }^{4,6}$
}

To cite: Stronks K, Hoeymans N, Haverkamp B, et al. Do conceptualisations of health differ across social strata? A concept mapping study among lay people. BMJ Open 2018;8:e20210. doi:10.1136/ bmjopen-2017-020210

- Prepublication history and additional material for this paper are available online. To view these files, please visit the journal online (http://dx.doi. org/10.1136/bmjopen-2017020210).

Received 27 October 2017 Revised 7 February 2018 Accepted 19 March 2018

Check for updates

${ }^{1}$ Department of Public Health, Amsterdam Public Health (APH) Research Institute, Academic Medical Center, University of Amsterdam, Amsterdam, The Netherlands

${ }^{2}$ Department of Public Health, City of Utrecht, Utrecht, The Netherlands

${ }^{3}$ Department of Social Sciences, section Communication, Philosophy and Technology, Wageningen University, Wageningen, The Netherlands

${ }^{4}$ National Institute of Public Health and the Environment (RIVM), Bilthoven, The

Netherlands

${ }^{5}$ Trimbos Institute, Netherlands Institute of Mental Health and Addiction, Utrecht, The Netherlands

${ }^{6}$ Tilburg University, Tilburg School of Social and Behavioral Sciences, Amsterdam, The Netherlands

Correspondence to

Dr Karien Stronks;

k.stronks@amc.uva.nl

\section{ABSTRACT}

Objectives The legitimacy of policies that aim at tackling socioeconomic inequalities in health can be challenged if they do not reflect the conceptualisations of health that are valued in all strata. Therefore, this study analyses how different socioeconomic groups formulate their own answers regarding: what does health mean to you? Design Concept mapping procedures were performed in three groups that differ in educational level. All procedures followed exactly the same design.

Setting Area of the city of Utrecht, the Netherlands. Participants Lay persons with a lower, intermediate and higher educational level ( $\pm 15 /$ group).

Results The concept maps for the three groups consisted of nine, eight and seven clusters each, respectively. Four clusters occurred in all groups: absence of disease/ disabilities, health-related behaviours, social life, attitude towards life. The content of some of these differed between groups, for example, behaviours were interpreted as having opportunities to behave healthily in the lower education group, and in terms of their impact on health in the higher education group. Other clusters appeared to be specific for particular groups, such as autonomy (intermediate/higher education group). Finally, ranking ranged from a higher ranking of the positively formulated aspects in the higher education group (eg, lust for life) to that of the negatively formulated aspects in the lower education group (eg, having no chronic disease).

Conclusion Our results provide indications to suggest that people in lower socioeconomic groups are more likely to show a conceptualisation of health that refers to (1) the absence of health threats (vs positive aspects), (2) a person within his/her circumstances (vs quality of own body/mind), (3) the value of functional (vs hedonistic) notions and (4) an accepting (vs active) attitude towards life.

\section{INTRODUCTION}

There is considerable evidence for socioeconomic inequalities in health within countries, to the disadvantage of people in lower socioeconomic groups. ${ }^{1-3}$ However, less research has focused on how people from different social strata conceptualise health. From a policy perspective, this is an important issue: the
Strengths and limitations of this study

- This is the first study to explore how people in different socioeconomic strata conceptualise health using the methodology of concept mapping.

- Concept mapping is a suitable methodology for our research question given that the concept of health has an evaluative dimension, informed by norms and values, involving different perspectives.

- The study identified similarities and differences in conceptualisations of health across strata, which can be used by policy makers to ensure that their policies reflect the conceptualisations of health that are valued in all strata.

- To increase external validity the same procedure should be repeated several times, in different areas and with different groups.

legitimacy of policies that aim at improving the health of people in lower socioeconomic groups can be challenged if these policies do not reflect the conceptualisations of health that are valued in all strata. For instance, if policies tacking health inequalities primarily aim at closing the gap in mortality, while people subjected to those policies understand health primarily as 'health-related quality of life', it is questionable whether the policy-focus on mortality has sufficient public support.

Health is a so-called 'thick concept', that is, its meaning has both descriptive and evaluative dimensions, in the sense that 'health' describes a condition which is at the same time valued. ${ }^{4}$ Given its evaluative dimension, the way people conceptualise health may differ between socioeconomic groups, to the extent that different socioeconomic groups are disposed to different practices (eg, value eating three meals a day or not), which in turn may be shaped by differences in living conditions (eg, availability of time and money to spend on dining).$^{56}$ Indeed, the few studies that investigated how health is conceptualised 
across social strata indicate relevant differences. For example, d'Houtaud and Field ${ }^{7}$ show that, in the lower socioeconomic groups, respondents emphasised health as the absence of sickness, whereas in higher socioeconomic groups health tended to be defined in terms of vitality. The latter finding was confirmed in a study by Peersman $\mathrm{et} \mathrm{al},{ }^{8}$ in which people were asked what conceptualisation of health they had in mind when answering the well-known single-item question on self-rated health.

However, knowledge in this field is limited regarding both the number of studies performed and the context in which they were performed as well as the methodology used. Therefore, this study aims to contribute to this body of knowledge by analysing how different socioeconomic groups formulate their own answers to the question: what does health mean to you?

\section{METHODS}

We used the methodology of concept mapping, which is a structured process to explore the conceptual ideas of a group about a complex multidimensional topic. The outcome is a concept map, that is, a visual representation of the group's thinking summarising all their ideas. Concept mapping is a suitable methodology for our research question given that: (a) the study subject is complex, that is,. the concept encompasses many different aspects and not all of those aspects, or the relationships between them, are clear; (b) there are different perspectives on a given subject, informed by different norms and values. ${ }^{9}$

For this study, the concept mapping approach described by Trochim was used, involving six steps: (1) preparation; (2) generation of statements; (3) structuring of statements; (4) representation of statements in concept maps; (5) interpretation and (6) utilisation. ${ }^{9}{ }^{10}$ Here we report on steps $1-5$.

\section{Step 1, preparation}

The study was performed in the western area of the city of Utrecht, which has various neighbourhoods largely representing the extent of the socioeconomic ladder. Participants were invited via leaflets distributed through letterbox drops, and handed out in local supermarkets, healthcare centres and community centres.

Socioeconomic status (SES) was indicated by educational level. People who responded positively were asked about their highest educational level attained. Then, three groups were distinguished based on the highest level of education attained: (1) higher: college degree up to academic degree; (2) intermediate: secondary school (intermediate and highest level) up to secondary vocational degree; (3) lower: no education up to secondary school (lowest level).

\section{Step 2, generation of statements}

One concept mapping session was arranged for each educational group (in Spring 2015); these sessions lasted about 4 hours each. Each of the sessions provided information on the study aim/background, the usual rules for brainstorming and the focus of the concept mapping procedure. Audio-recordings of the sessions were made to enable confirmation of the statements and editing. We chose to formulate the brainstorm focus prompt as follows: 'Health means to me...', indicating that we were seeking a person's own thoughts and ideas. During the sessions, statements were uniquely numbered, entered into a computer and displayed on a large screen; this allowed all participants to see the set of statements as they evolved. Double or overlapping statements were deleted during the sessions, in consultation with the participants.

After collecting the statements from each participant, the moderator asked the group to come up with statements that had not been mentioned before. The moderator also mentioned aspects of health emerging from earlier studies in the Netherlands on health, ${ }^{112}$ in case they had not been mentioned by the participants. This was the case for a maximum of three statements only. If there was at least one participant who recognised the additionally mentioned aspect as important, it was added to the list (after it had been reformulated into a statement by the group as a whole). The list was considered to be complete when no new statements were generated.

\section{Step 3, structuring of statements}

For the structuring process, each generated statement was uniquely numbered and printed on a separate index card. Each participant received two complete sets of cards. For the first structuring task, that is, the sorting, each participant individually grouped the cards of one set into piles that associatively 'belong together in a way that makes sense to you', and labelled these piles, based on their content. Participants were not limited in the number of piles they formed, nor in the number of statements in each pile. For the second task, that is, the rating, the participants were asked to rate each statement on a 5-point Likert-type response scale, ranging from 1 (least important) to 5 (most important), by dividing the index cards into five equal piles of increasing importance for understanding what health is.

\section{Step 4, representation of statements in concept maps}

After the meetings, the statements of each group and the individual structuring data were entered in the software program 'Concept System Global Max'. Using two-dimensional non-metric multidimensional scaling of the similarity matrix of the aggregated sorted data, the software produces a two-dimensional plot of the statements. ${ }^{9} 0^{10}$ With regard to the content, the greater the distance between two statements (dots on the pointmap), the weaker the statements are associated with each other. The software then uses the coordinates of the statements on the map as input for a cluster analysis. Anticipating step 5, that is, interpretation, the software enables for manually inspecting the different cluster solutions and proposes labels for each cluster, based on the participants' labels. 


\section{Step 5, interpretation}

The interpretation step was done by nine researchers involved in the project, during two meetings. Within this group, it was discussed and decided which cluster solution made most sense, given the content of the statements within the clusters. For each educational group, we started with a map representing 14 clusters and labelled these clusters based on their content (ie, statements within the clusters) and suggested labels by the participants, as given by the software. Using a cluster tree, we interpreted every reduction in the number of clusters. A reduction implied that statements of two clusters were merged into one new cluster. We assessed whether this new cluster summarised the data in a meaningful way without losing important distinctions as expressed in the statements. If so, the new cluster was labelled based on its content. As soon as a further merge led to a loss of meaningful distinctions, the optimal number of clusters was achieved. Occasionally, we also used Bridging Values. This value indicates whether the statement was sorted with others that are close to it on the map (low value) or whether it was sorted with items that are further away on the map (high value). In a few cases, based on these values as well as an in-depth analysis of the content of the statements, we redraw the borders of clusters to make these clusters better to interpret. Consensus was reached by discussion, in an iterative process. To promote an open discussion and preclude bias, we purposely searched for diversity in the group, regarding previous experience with the concept mapping technique, disciplinary background (public health, philosophy, social sciences) and working environment (academic setting, non-academic research, public health policy and public health practice). After consensus was reached on the clusters in each group, the researchers compared each of the clusters within one group with a similar cluster found in the two other groups. A comparison was made regarding differences and commonalities in order to ensure that similar cluster-interpretations were made for the different educational groups.

The final step was to compare the three concept maps on similarities and differences. The group compared the type of clusters, the wording of the labels of the clusters and statements within the clusters and the ranking of the clusters and statements. These comparisons were based on a face-value analysis. Consensus was reached by discussion.

\section{Ethical approval}

The study was judged to need no further review by a local ethic committee because the Medical Research Involving
Human Subjects Act does not apply to our concept-mapping study: participants were recruited on a volunteer basis and were not required to undergo physical examination. We obtained written informed consent from all participants.

\section{RESULTS}

\section{Participants in steps 1 to 3}

A total of 46 persons participated: 16 in both the higher and intermediate education group, and 14 in the lower education group (table 1). Eight people did not participate in step 2 (generation of statements) but did rank and sort the statements (step 3) that were generated during the session of the educational group they belonged to. They performed this task at home, with two piles of cards and clear instructions. The age distribution of the groups differed, that is, the lower educated group were older than the other two groups. In all three groups, the majority of participants was female.

\section{Three concept maps: content of statements, and clusters}

The number of statements generated ranged from 74 in the lower and higher educational group, to 87 in the intermediate education group. In the online supplementary appendix, table A1 to A3 show the statements within each cluster and the average ranking of the clusters, based on the ranking of the statements. The three concept maps are presented in figure 1 . The concept maps for the lower, intermediate and higher educational group consist of nine, eight and seven clusters, respectively. Each cluster represents 5-17 statements, indicated by dots in figure 1 .

\section{Description of the concept maps}

All groups identified a cluster related to the absence of disease and disabilities with statements referring to disease, pain, discomfort, disabilities and functional abilities (table 2). In the lower educational group, emphasis was on the absence of disease or physical complaints, whereas in the intermediate and (to a lesser extent) the higher educational group, most statements reflected aspects of functional abilities (eg, being physically able to do what one wants). Furthermore, in the higher educational group, items on self-perceived health (eg, being vital) are also included in this cluster, besides a separate cluster on 'perceived health', which is located close to the cluster on functioning and absence of disease (figure 1). Perceived health as a cluster was absent in the other groups.

Table 1 Characteristics of the three groups, by educational level

\begin{tabular}{lllll}
\hline Education group: & n (step 3 only) & Educational level & Mean age (years) & $\begin{array}{l}\text { Percentage (\%) of } \\
\text { women }\end{array}$ \\
\hline Higher educational level & $16(5)$ & 15 high/1 intermediate & 44 & 75 \\
Intermediate educational level & $16(2)$ & 13 intermediate/3 high & 49 & 56 \\
Lower educational level & $14(1)$ & 14 low & 69 & 79 \\
\hline
\end{tabular}




\section{A Lower educational group}

\begin{tabular}{ll}
\hline Number of layers & $\begin{array}{l}\text { Average rating of } \\
\text { all statements } \\
\text { within a cluster }\end{array}$ \\
\hline 1 & 2.74 to 2.88 \\
\hline 2 & 2.88 to 3.02 \\
\hline 3 & 3.02 to 3.17 \\
\hline 4 & 3.17 to 3.31 \\
\hline 5 & 3.31 to 3.45 \\
\hline
\end{tabular}
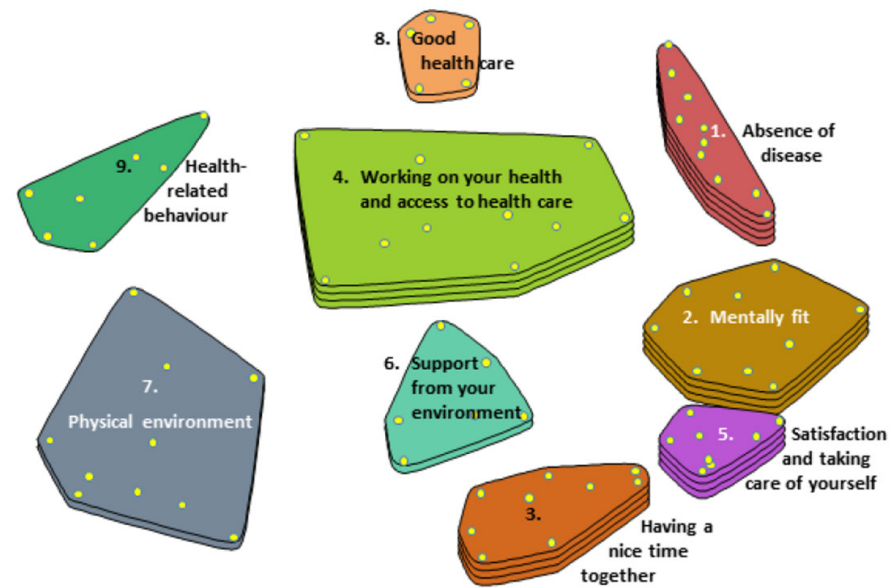

\section{B Intermediate educational group}

\begin{tabular}{|c|c|}
\hline Number of layers & $\begin{array}{l}\text { Average rating of } \\
\text { all statements } \\
\text { within a cluster }\end{array}$ \\
\hline 1 & 2.85 to 3.03 \\
\hline 2 & 3.03 to 3.21 \\
\hline 3 & 3.21 to 3.39 \\
\hline 4 & 3.39 to 3.57 \\
\hline 5 & 3.57 to 3.75 \\
\hline
\end{tabular}

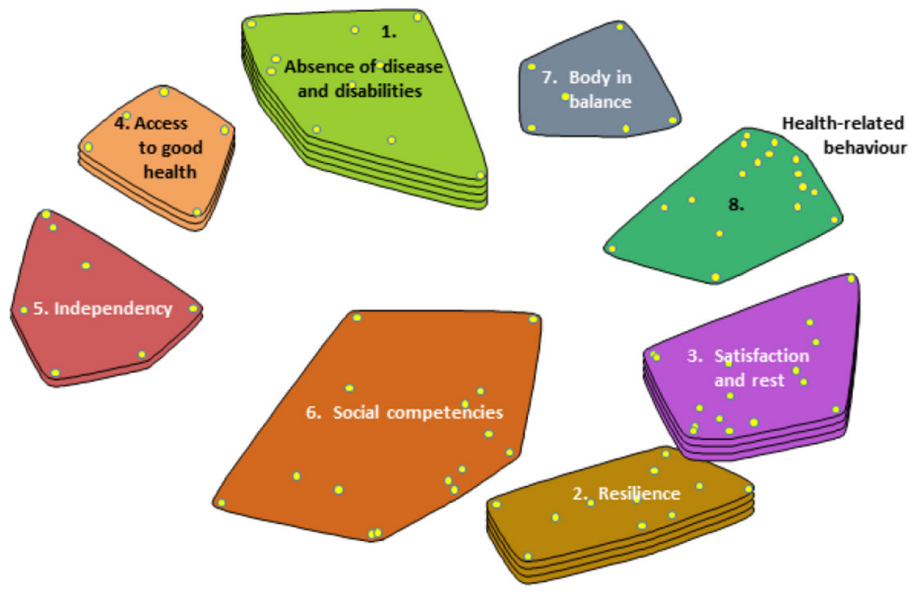

\section{Higher educational group}

\begin{tabular}{ll}
\hline Number of layers & $\begin{array}{l}\text { Average rating of } \\
\text { all statements } \\
\text { within a cluster }\end{array}$ \\
\hline 1 & 2.96 to 3.07 \\
\hline 2 & 3.07 to 3.19 \\
\hline 3 & 3.19 to 3.31 \\
\hline 4 & 3.31 to 3.43 \\
\hline 5 & 3.43 to 3.55 \\
\hline
\end{tabular}

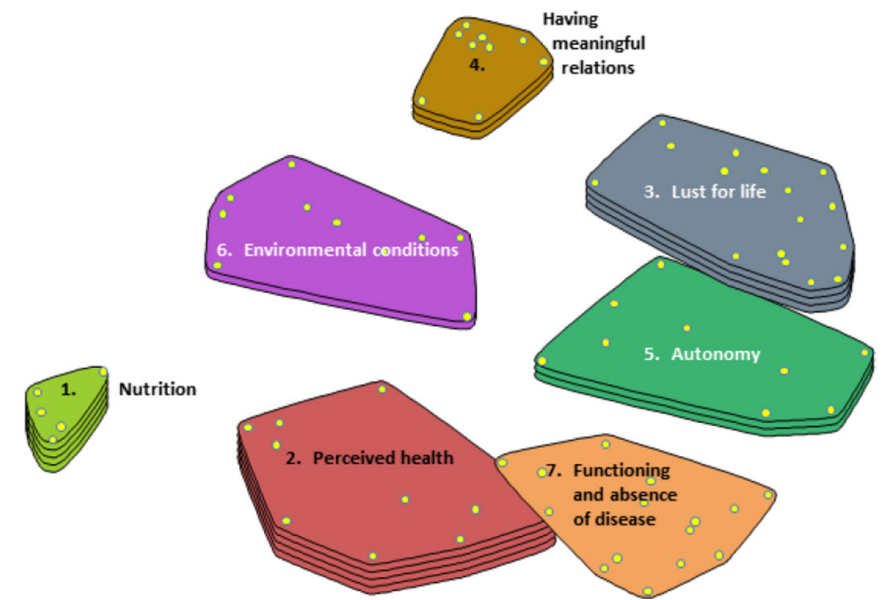

Figure 1 Concept maps for three educational groups, showing the statements, grouped into clusters; the smaller the distance between two statements or clusters, the stronger they are associated with each other; a higher number of layers indicates an increasing importance of that cluster for understanding what health is. 
Table 2 Description of the clusters for the three educational groups

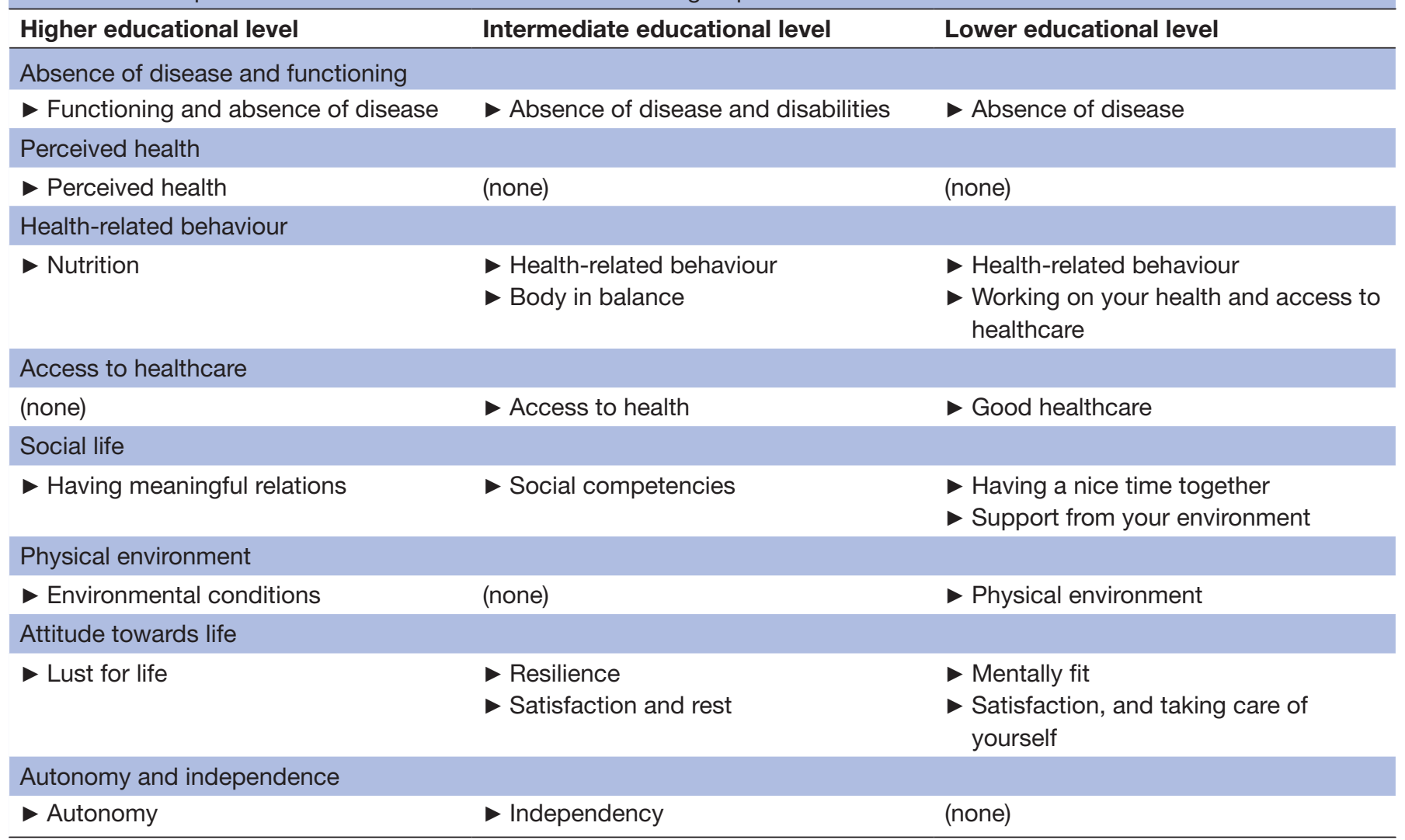

Clusters related to health-related behaviour were present in all groups. In the intermediate education group, the cluster contains a wide range of behaviours. Additionally, in this group, also the cluster 'body in balance' consists of health-related behaviours, in particular in relation to their impact on health (eg, having a good sleep). In the higher educational group and (to a lesser extent) in the lower education group, the health-related behaviour cluster is restricted to nutrition. In the higher education group, statements on other health-related behaviours were grouped in the cluster 'perceived health', located next to the nutrition cluster (figure 1). This suggests that these items were interpreted in terms of their impact on physical and mental health. In the lower educational group, other aspects of health-related behaviour were combined with statements on having access to good healthcare in one cluster 'access to healthcare', which was located next to the health-behaviour cluster (figure 1). This seems to indicate that statements on health-related behaviour were largely seen as 'having opportunities' to behave in a healthy way. In addition, the concept map of the lower educational group holds another cluster on healthcare, namely 'good care' with statements such as 'getting attention from your doctor' and 'getting equal treatment'. A similar cluster was found in the intermediate education group, although that cluster also concerns access to goods other than healthcare (eg, access to green space), and is therefore labelled as 'access to health'. The higher education group had no cluster on healthcare.
Furthermore, all groups also conceptualised health in terms of having a satisfactory social life. In the low and intermediate education group, the emphasis was on having a nice time together, whereas in the higher educational group the focus was on having meaningful relationships.

Clusters related to physical environment contain statements that refer to a healthy house, workplace and environment. The intermediate education group does not have a cluster on physical environment. Their statements related to physical environment are part of other clusters (ie, body in balance and access to health).

In all educational groups, also one's attitude towards life was considered to be an aspect of health. The higher education group clustered statements as having lust for life, being able to enjoy, accept yourself, being able to be independent and being able to cope. The intermediate education group grouped this type of statement into two clusters, which were located next to each other, namely 'resilience' and 'satisfaction and rest' (figure 1). The same applies to the lower educational level, where the two closely related clusters referred to 'mental fitness' and 'satisfaction and taking care of yourself' (figure 1). In the latter group, the wording of many of the statements focuses on satisfaction and acceptance of life, for example, 'relaxation' and 'being comfortable in your skin'.

In addition, the concept maps of the higher and intermediate educational groups hold a cluster on autonomy and independence. In the intermediate education group, 


\begin{tabular}{|c|c|c|c|}
\hline Education & Higher & Intermediate & Lower \\
\hline \multicolumn{4}{|c|}{ Ranking of the clusters } \\
\hline 1 (highest) & Nutrition & Absence of disease and disabilities & Absence of disease \\
\hline 2 & Perceived health & Resilience & Mentally fit \\
\hline 3 & Lust for life & Satisfaction and rest & Having a nice time together \\
\hline 4 & Having meaningful relationships & Access to good health & $\begin{array}{l}\text { Working on your health and access } \\
\text { to healthcare }\end{array}$ \\
\hline 5 & Autonomy & Independency & $\begin{array}{l}\text { Satisfaction and taking care of } \\
\text { yourself }\end{array}$ \\
\hline 6 & Environmental conditions & Social competencies & Support from your environment \\
\hline 7 & Functioning and absence of disease & Body in balance & Physical environment \\
\hline 8 & & Health-related behaviour & Good healthcare \\
\hline 9 (lowest) & & & Health-related behaviour \\
\hline \multicolumn{4}{|c|}{ Ranking of the statements: five highest ranked } \\
\hline 1 (highest) & Feel physically and mentally well & Being mentally clear & Being mentally healthy \\
\hline 2 & Having lust for life & Mental rest & Having no stress \\
\hline 3 & Being able to enjoy & Being able to enjoy & Having no chronic disease \\
\hline 4 & Being able to be independent & Having sufficient energy & Getting attention from your doctor \\
\hline 5 (lowest) & Sufficient exercise & Having no pain & $\begin{array}{l}\text { Having sufficient money for healthy } \\
\text { food }\end{array}$ \\
\hline
\end{tabular}

this includes statements such as 'being mentally clear' and 'being independent from the help of others'. The higher educational group mentioned 'being independent' and 'making one's own decisions'.

\section{Ranking of clusters and statements}

The clusters were ranked, based on the average rating of all statements within a cluster. The layers in figure 1 indicate the average rating. The relative ranking of the clusters differs between the groups (table 3), with the pattern for the higher educational group being the most distinct. Whereas 'absence of disease' is ranked highest in the intermediate/lower education groups, the group with high education ranked this aspect lowest. The pattern was reversed for clusters on health-related behaviour. Similarities between the groups include the relatively high ranking of the clusters on attitude towards life, and the ranking of the satisfactory social life in the middle.

In all groups, mental health is ranked as the single most important statement (table 3). Notable is that, also in the group with the higher educational level, the five statements that are ranked highest express 'positive' states (eg, lust for life), whereas the group with the lower/intermediate educational level formulate two and one, respectively, of the five highest ranked statements in a negative manner (eg, having no stress).

\section{DISCUSSION}

In all three groups health was conceptualised as a multidimensional concept. Four clusters occurred in all groups, that is, absence of disease and functioning, health-related behaviours, social life and attitude towards life. Differences were also observed. First, some dimensions appeared to be specific for particular educational groups, for example, access to good healthcare was specific for the lower/intermediate education group, autonomy or independence for the intermediate/higher education group and perceived health for the higher education group. Second, the content of some clusters differed. The cluster 'absence of disease' was literally used in the lower education group, but was broadened to 'functioning' in the intermediate education group, and further broadened to 'self-perceived health' in the higher education group. Social life was conceptualised in the lower education group in terms of 'having a nice time together' to 'having meaningful relationships' in the higher education group. 'Attitude towards life' in the higher educational group suggests 'lust for life', and shifted to an emphasis on satisfaction and acceptance of life in the lower education group. Finally, differences were observed in ranking: the clusters that relate to health behaviour were ranked highest in the higher education group, and lowest in the other groups, whereas the ranking was reversed for the absence of disease dimension. In addition, positive aspects were ranked higher in the higher education group versus negative aspects in the lower education group.

\section{Interpretation of similarities}

The finding that all socioeconomic groups consider health as a multidimensional concept was also reported by Simon et al. ${ }^{14}$ They investigated what Dutch people with different levels of education took into consideration 
when answering a question on self-rated health. Both their findings and ours are in contrast to the results of Calnan and Johnson, ${ }^{15}$ whose lower-class group saw health as one-dimensional, in terms of 'getting through the day' and 'never being ill', whereas the higher-class group mentioned also other dimensions as indicated by terms such as 'feeling strong' and 'being active'. This difference between the outcome of Calnan and Johnson's and our study might be explained by the fact that the participants in their study were asked in the abstract about health, in the setting of a personal interview. The lower-class group might have been less used to give their abstract views and therefore might have come up with single dimensions only. Mentioning multiple dimensions might have been much easier for the respondents in our study, who met in a group setting, and were explicitly asked to generate multiple statements.

All our socioeconomic groups conceived health in both subjective and objective terms. 'Feeling happy', 'feeling good' or 'accepting your handicap' are examples of subjective dimensions, in which the perspective of the individual determines the health judgement. Examples of objective dimensions, that is, defined by an external criterion, include 'having no chronic condition' and 'no smoking'.

\section{Interpretation of differences}

However, differences were also observed. First, the lower/ intermediate education groups were more inclined to define health negatively, as 'not having a disease', that is, as an absence of health threats. The highest education group predominantly preferred positive framing. This might reflect actual differences in health between socioeconomic groups, with people in lower socioeconomic groups having a much higher risk of suffering from a health problem themselves, or having people in their environment that suffer from health problems. Thus, the actual circumstances in which people live are important for how they conceptualise an abstract notion such as health.

Second, the conditions that were mentioned as essential for having access to good health differed between the socioeconomic groups. Whereas the higher/intermediate education group referred (in five of seven and six of eight clusters, respectively) to the quality of the body or mind (eg, body in balance), the lower education group framed these in terms of a person within his/her circumstances (six of the nine clusters). The top five of highest ranked statements showed a similar pattern. A similar result was reported by d'Houtaud and Field, ${ }^{7}$ where conditions such as 'medical supervision' were more often mentioned in the lower socioeconomic groups. Also, in the present study, the way in which similar items were formulated in different socioeconomic groups seems to support this distinction. For example, the cluster in the lower education group with the heading 'support from your environment' is mirrored in the qualification of 'autonomy' and 'being able to care for yourself' as an asset of the individual in the higher education and intermediate education group, respectively.

Third, also the value of being in good health seems to differ between groups. ${ }^{16}$ In accordance with studies by d'Houtaud and Field ${ }^{7}$ and Calnan and Johnson, ${ }^{15}$ the highest socioeconomic group was more inclined to perceive health in terms of what d'Houtaud and Field called 'hedonistic use of life', such as 'good mental equilibrium'. In our study, examples include the cluster 'lust for life', in which statements referred to the meaning of life, grip of life and vitality. In contrast, in the lowest socioeconomic group the conception of health corresponded with more 'functional' notions of health, in terms of 'getting through the day' and 'being able to work'. ${ }^{15}$

Finally, some statements seem to reflect a different attitude, from a more active attitude on life in the highest socioeconomic group to more acceptance of life and what it brings, in the intermediate/lower education group. An example of the latter includes a statement such as 'having fun together'. An example of the former includes 'having lust for life'. This is probably a reflection of the differences in socioeconomic circumstances that the groups face. ${ }^{16}$ The more difficult the circumstances, the more common it may be to see health as something that should be 'just good enough' to face challenges.

\section{Methodological limitations}

There are several advantages of concept mapping compared with (semi-structured) interviews to lay views on health. There is, for instance, no question-answer structure, except from the open prompt that participants had to complete. This brainstorm setting ensures minimal intervention from the moderator, allowing the vocabulary of the participants to remain largely intact. Whereas in focus groups the more dominant voices might steer the discussion in a particular direction, in concept mapping this dynamic is restricted by the initial individual brainstorm, the brainstorming rules and the individual structuring process. This individual input ensures that the perspective of each participant is equally reflected in the final concept map.

However, as with focus groups, the result of a concept mapping study is the perspective of a particular group, raising the question of external validity. This is important because the groups in the present study may not be representative for the various educational groups in the Netherlands, given the small number of participants, their regional origin, the sex distribution and the selection method used. A more fully saturated concept to increase external validity might be achieved by repeating the same procedure several times, in different areas and with different groups. ${ }^{17}$ Furthermore, in a concept mapping study, the possibility to examine what is meant by a certain statement or expression by the participants is relatively limited. In our study, this was particularly so as we decided not to involve the participants in the representation and interpretation stage, mainly for practical reasons. As a consequence, we as researchers felt a certain level of 
uncertainty as to the exact interpretation of the different clusters, in view of, for example, the different type of statements that clustered together. However, as discussed in the 'Method' section, we strived for diversity in the group of researchers to promote an open discussion and preclude bias. In addition, the advantage of the fact that we as researchers have carried out the interpretation stage, is the comparability of the maps across education groups. Moreover, the broad conceptualisation of health, with various clusters is confirmed in other studies. This includes a study by Huber $e t a l^{12}$ on indicators for a new, dynamic concept of health, as well as a study using the same methodology as ours, but performed in five other Dutch cities (Flinterman et al, unpublished). In addition, the clusters and the distinctions that we identified in the interpretation of the results as well as the differences between socioeconomic groups therein, corroborate those identified earlier. ${ }^{7151618} \mathrm{~A}$ third weakness in our study concerns the differences in age between the three groups. The fact that the lowest educational group was on average 20 years older than the other groups raises the question whether the differences in the final concept maps could actually be attributed to differences in age rather than in SES. We consider this not to be very likely, however. Although Simon et al showed that older people more often had a multidimensional concept of health compared with younger people, the study by Peersman et al, in which both age and educational differences have been analysed, indicates only small differences in the way people of different age groups conceptualise health. ${ }^{8}$ Furthermore, as discussed above, our findings correspond with the results of previous studies. Finally, we observed similarities between the lower and intermediate socioeconomic groups, such as the inclination to define health negatively, despite substantial age differences between these group.

A fourth weakness that needs to be discussed concerns the choice for educational level as an indicator of SES. In studies on health inequalities, education is a frequently used indicator of adult SES. ${ }^{19}$ It is strongly associated with occupational level and income, but has the advantage of being available for each individual, also, for example, for those without a paid job. Although different indicators might indicate different aspects of someone's position, ${ }^{19}$ we do not expect our results to be biased by the choice for this indicator, as the conceptualisation of the concept mapping groups reflect aspects closely related to educational level (such as autonomy), and aspects related to income and occupational level (eg, having access to healthcare or living in a healthy environment).

\section{Implications}

If confirmed in future studies, our results could be used to critically consider the legitimacy of policies aimed at tackling health inequalities. We give three examples, to illustrate the type of implications that we foresee. First, given that health has been conceptualised as a multidimensional phenomenon in all groups, it might be argued that health policy goals need to cover a broad spectrum of health aspects, ranging from, for example, chronic conditions to self-perceived health to vitality. Second, the concept maps of lower socioeconomic groups in particular support health policy goals that also include the conditions that shape health, as in the case in the WHO social determinants of health approach. Third, the differences between socioeconomic groups in the way health is conceptualised, challenge the legitimacy of policies that are based on a notion of health that resonates the conceptions that are valued in higher socioeconomic groups in particular, such as 'good mental equilibrium' or 'lust for life'.

\section{CONCLUSIONS}

The conceptualisation of health, although multidimensional in all socioeconomic groups, showed differences between these groups. In our study, people in lower socioeconomic groups were more likely to show a conceptualisation of health that refers to: (1) the absence of health threats (vs positive aspects), (2) a person within his/her circumstances (vs quality of own body/mind), (3) the value of functional (vs hedonistic) notions and (4) an accepting (vs more active) attitude towards life and what it brings.

Acknowledgements The authors would like to thank Marie-Louise Essink-Bot, who sadly passed away in May 2016, and Anja Koornstra for their help in interpreting the concept maps. Foremost, the authors thank all participants of the study.

Contributors KS developed the idea, participated in the design of the study, the data collection and the interpretation of the concept maps and drafted the manuscript. NH participated in the design of the study, in the data collection and in the interpretation of the concept maps and drafted the manuscript. FRJdH led the design of the data collection and data analyses and interpretation of the concept maps, and contributed to the revision of the draft manuscript. MV developed the idea, participated in the design of the study and in the interpretation of the concept maps and contributed to the revision of the draft manuscript. BH, MJHvB-M and HAMv0 participated in the design of the study, in the data collection and in the interpretation of the concept maps, and contributed to the revision of the draft manuscript. $\mathrm{HG}$ was involved in the interpretation of the concept maps and contributed to the revision of the draft manuscript. All authors have seen and approved the final manuscript.

Funding The authors were financially supported by the Netherlands Organization for Scientific Research (NW0), grant number: 319-20-002.

Competing interests None declared.

Patient consent Obtained.

Provenance and peer review Not commissioned; externally peer reviewed.

Data sharing statement The datasets generated and analysed are available from the corresponding author on request. Informed consent for data sharing was not obtained, but the presented data are anonymised and risk of identification is very low.

Open Access This is an Open Access article distributed in accordance with the Creative Commons Attribution Non Commercial (CC BY-NC 4.0) license, which permits others to distribute, remix, adapt, build upon this work non-commercially, and license their derivative works on different terms, provided the original work is properly cited and the use is non-commercial. See: http://creativecommons.org/ licenses/by-nc/4.0/

(C) Article author(s) (or their employer(s) unless otherwise stated in the text of the article) 2018. All rights reserved. No commercial use is permitted unless otherwise expressly granted. 


\section{REFERENCES}

1. Mackenbach JP, Stirbu I, Roskam AJ, et al. European Union Working Group on Socioeconomic Inequalities in Health. Socioeconomic inequalities in health in 22 European countries. N Engl J Med 2008;358:2468-81.

2. Jagger $\mathrm{C}$, Weston $\mathrm{C}$, Cambois $\mathrm{E}$, et al. Inequalities in health expectancies at older ages in the European Union: findings from the Survey of Health and Retirement in Europe (SHARE). J Epidemiol Community Health 2011;65:1030-5.

3. Mäki N, Martikainen P, Eikemo T, et al. Educational differences in disability-free life expectancy: a comparative study of longstanding activity limitation in eight European countries. Soc Sci Med 2013;94:1-8

4. Haverkamp B, Bovenkerk B, Verweij MF. A practice-oriented review of health concepts. J Med Philos 2018.

5. Burgard SA, Chen PV. Challenges of health measurement in studies of health disparities. Soc Sci Med 2014:106:143-50.

6. Burnett PJ, Veenstra G. Margins of freedom: a field-theoretic approach to class-based health dispositions and practices. Sociol Health IIIn 2017;39:1050-67.

7. d'Houtaud A. Field MG The image of health: variations in perceptions by social class in a French population. Sociol Health IIIness 1984;1:30-60.

8. Peersman W, Cambier D, De Maeseneer J, et al. Gender, educational and age differences in meanings that underlie global self-rated health. Int J Public Health 2012;57:513-23.

9. Trochim WMK. An introduction to concept mapping for planning and evaluation. Eval Program Plann 1989;12:1-16.
10. Kane M, Trochim WMK. In: Bickman L, Rog DJ, eds. Concept mapping for planning and evaluation. Thousand Oakes: Sage Publications, Inc, 2007.

11. Kooiker SE. Nederlanders aan het woord over gezondheid en gezond leven. Achtergrondrapport bij de VTV 2010 Van gezond naar beter. Bilthoven/Den Haag: RIVM/SCP, 2011.

12. Huber M, van Vliet M, Giezenberg M, et al. Towards a 'patientcentred' operationalisation of the new dynamic concept of health: a mixed methods study. BMJ Open 2016;6:e010091.

13. Manual Ariadne 3.0. http://talcott.nl/onewebmedia/Handboek\% 20gebruik\%20ARIADNE\%203.0.pdf

14. Simon JG, De Boer JB, Joung IM, et al. How is your health in general? A qualitative study on self-assessed health. Eur J Public Health 2005;15:200-8.

15. Calnan M, Johnson B. Health, health risks and inequalities: an exploratory study of women's perceptions. Sociol Health IIIn 1985;7:55-75.

16. Lawton J. Lay experiences of health and illness: past research and future agendas. Sociol Health IIIn 2003;25:23-40.

17. van Bon-Martens MJH, van de Goor IAM, van Oers HAM. Concept mapping as a method to enhance evidence-based public health. Eval Program Plann 2017;60:213-28.

18. Hughner RS, Kleine SS. Views of Health in the Lay Sector: A Compilation and Review of How Individuals Think about Health. Health 2004;8:395-422.

19. d'Errico A, Ricceri F, Stringhini S, et al. Socioeconomic indicators in epidemiologic research: A practical example from the LIFEPATH study. PLoS One 2017;12:e0178071. 